\title{
EFEK MEDIASI TERHADAP KEPUASAN KINERJA KARYAWAN DENGAN HUBUNGAN KEPEMIMPINAN YANG EFEKTIF DALAM SITUASI TERTENTU
}

\author{
Nama : Haqqan amien maziun \\ Email : haqqanamien1@gmail.com
}

Sistem pengawasan manajemen yang baik, dapat mengindikasikan wujudnya satu sistem pengawasan yang dapat memaksimalkan pengaruh manajemen (Lowe, 1971). Selaras dengan pandangan tersebut, (Fisher, 1995) menjelaskan pengawasan merupakan suatu aktivitas dalam keadaan tertentu dapat mendorong organisasi untuk mencapai apa yang dicita-citakan atau diharapkan pada waktu tertentu dimasa depan. Seterusnya, menurut (Hambrick, 1985) terdapat tiga asas pendekatan di dalam mengkaji pengaruh sistem pengawasan manajemen ke atas kinerja yaitu pendekatan kontingensi, pendekatan keadaan umum dan perdekatan keadaan khusus.

Dalam penjelasan (Pratono, "Strategic orientation and information technological turbulence Contingency perspective in SMEs, 2016) menjelaskan tentang bagaimana UKM (Unit Kesehatan Masyarakat) menangani perubahan teknologi informasi. Studi ini menarik kesimpulan untuk berpendapat bahwa SO (strategic orientation) pada peluang bisnis datang ke batasan di bawah informasi TT (technological turbulence). Mengenali efek moderator informasi TT pada hubungan antara SO (strategic orientation) dan FP (firm performance) memungkinkan mengklarifikasi kontinjensi kunci FP. Penelitian ini menegaskan hubungan heterogen antara kembalinya SO dan FP. Temuan ini harus mendorong manajer UKM dan pembuat kebijakan untuk membayar kepedulian dalam kemampuan teknologi yang akan memungkinkan UKM untuk mendapatkan keunggulan kompetitif yang berkelanjutan. Memang konsep seperti pengakuan peluang dan kemampuan dinamis menjadi pusat keberhasilan UKM, terutama dengan perilaku kewirausahaan. Ketika studi menyangkut dampak TT pada hubungan antara SO dan FP, ulasan tentang faktor kontinjensi generik secara singkat membahas untuk menggambarkan signifikansi mereka.

Penelitian dalam jurnal ini menjelaskan tentang catatan perilaku kewirausahaan dan memberikan bukti empiris untuk mengonfirmasi bahwa perilaku mengambil risiko secara positif mempengaruhi kinerja yang tegas. Mengingat bahwa tata kelola risiko tidak terbatas pada praktik tradisional, penelitian ini memajukan pekerjaan sebelumnya tentang perilaku mengambil risiko pada tingkat perusahaan dalam turbulensi IT. Penelitian ini suka menunjukkan bahwa berbagai kondisi turbulensi IT menyebabkan dampak yang berbeda dari perilaku mengambil risiko pada kinerja yang tegas. penelitian ini berkaitan dengan peran mediasi kemampuan penetapan harga untuk pemahaman yang lebih baik tentang hubungan yang rumit antara perilaku mengambil risiko dan kinerja yang tegas (Pratono, 2018).

Dalam penelitian ini (Pratono, Ratih, \& Arshad, 2018) turbulensi teknologi mempengaruhi inisiatif untuk mempromosikan otonomi kewirausahaan dengan dua pertimbangan (1) peran mediasi kemampuan penetapan harga untuk mendukung otonomi kewirausahaan untuk mencapai kinerja dan (2) efek moderasi turbulensi teknologi pada efek mediasi kemampuan penetapan harga. Hasilnya menyumbangkan karya-karya pada perilaku kewirausahaan, yang tidak hanya menjelaskan bagaimana turbulensi teknologi mempengaruhi inisiatif untuk mempromosikan otonomi kewirausahaan tetapi juga menjelaskan bagaimana perusahaan dengan otonomi kewirausahaan mencapai kinerja dengan mengembangkan kemampuan penetapan harga.

Menurut (Brown, 1995) , gaya komunikasi partisipatif dalam operasi bisnis sangat penting bagi perusahaan untuk mendapatkan inovasi. (Dougherty, 1992) menyarankan bahwa komunikasi 
partisipatif akan meningkatkan jumlah informasi secara langsung. Selain itu, komunikasi berguna dalam membangun kerja sama tim untuk mengatasi berbagai hambatan untuk berkomunikasi di antara anggota organisasi. Komunikasi ini akan mengurangi kesalahpahaman dan hambatan pertukaran informasi sehingga kecepatan dan produktivitas akan meningkatkan operasi bisnis. Brown dan (Brown, 1995) berpendapat bahwa ketika anggota tim berkomunikasi cukup sering, mereka mengembangkan kapasitas absorptive lebih mungkin sehingga mereka menjadi lebih efisien dalam memperoleh dan menggunakan informasi. Kapasitas absorptive ini juga akan meningkatkan produktivitas dan kecepatan pengembangan produk baru. (Rahab, 2012)

Mediating effect adalah dampak yang diberikan oleh suatu kejadian Variabel mediator yang saling menghubungkan Independent variable dan Dependent Variabel. Jika hubungan antara variabel dependen $\mathrm{Y}$ dan variabel independen $\mathrm{X}$ adalah fungsi dari variabel $\mathrm{M}$, maka $\mathrm{M}$ disebut sebagai variabel moderator. Itu berarti hubungan antara $\mathrm{Y}$ dan $\mathrm{X}$ dipengaruhi oleh variabel ketiga $\mathrm{M}$. Moderator dapat menjadi variabel kualitatif atau kuantitatif, dan dapat mempengaruhi arah (positif atau negatif) dan kekuatan hubungan antara variabel dependen dan independen. Saat menguji efek moderatoring, variabel independen dan variabel moderator perlu dipusatkan, karena nilai sampel variabel dikurangi rata-ratanya. (Wang, Wang, Chen, Pan, \& Zhang, 2020)

Kepercayaan atau Trust dalam sebuah perusahaan dapat membangun fundamental suatu perusahaan, distributor dan pemasok agar dapat saling memahami satu sama lain. Kepercayaan atau Trust memiliki fungsi sebagai Mediating Variabele. Kepercayaan menberikan full mediating effect terhadap firm performance dan Social Network Structure. Dampak kepercayaan atau Trust bagi perusahaan adalah dengan meningkatnya kualitas jaringan kinerja perusahaan dan mendorong perusahaan untuk berinvestasi sumber daya lebih banyak lagi. (Pratono, 2018)

Inter-organizational Learning (IOL) berfungsi sebagai Mediating Variable dalam mendukung hubungan antara Variabel Independen Green Entrepreneurial Orientation (GEO) dan Market Orientation (MO) dan firm competitive advantage. Penelitian ini menggunakan data primer yang diperoleh dari sebuah survei. Populasi yang ditargetkan adalah industri manufaktur di mana Kementerian Perdagangan dan Industri Indonesia menyediakan basis data industri. Berdasarkan database, distribusi kuesioner melibatkan beberapa surveyor untuk mendapatkan konfirmasi dari responden apakah perusahaan menyelenggarakan kolaborasi antarorsional di penelitian dan pengembangan. Untuk mendapatkan objektivitas data, pengumpulan data mengandalkan respon administratif mandiri di mana surveyor tidak terlibat dalam mengisi kuesioner. Setelah penyaringan data, kumpulan data akhir memiliki 280 respons (ukuran sampel), yang berasal dari manajer yang sukarela untuk menggambarkan letaknya. (Pratono, Darmasetiawan, Yudiarso, \& Jeong, 2019)

penelitian ini bergantung pada PLS-SEM yang menggunakan data primer yang dikumpulkan untuk memperkirakan hubungan jalur. Model jalur dikembangkan berdasarkan literatur sebelumnya, yang berpendapat bahwa variabel laten terkait satu sama lain. GEO dan MO di sisi kiri model jalur diyakini sebagai penentu utama keunggulan kompetitif yang tegas. IOL berfungsi sebagai variabel mediasi untuk mendukung hubungan antara variabel independen (GEO dan MO) dan keunggulan kompetitif yang kuat. (Pratono, Darmasetiawan, Yudiarso, \& Jeong, 2019) 


\section{Bibliography}

Brown, S. a. (1995). Product development: past research, present findings, and future directions. The Academy of Management Review, 20(2), 343-378.

Dougherty, D. (1992). A practice-centered model of organizational renewal through product innovation. Strategic Management Journal, 13(8), 77-92.

Fisher, J. (1995). Contingency-based research on management control systems: categorization by level of complexity. Journal of Accounting Literature, 14, 24-53.

Hambrick, D. \&. (1985). Toward an empirical prioritization of contingency variables for business strategy. Academy of Management Journal, 28, 763-788.

Lowe, E. (1971). On the idea of a management control system: integrating accounting and management control. Journal of Management Studies, 8(1), 1-12.

Pratono, A. H. (2016). "Strategic orientation and information technological turbulence Contingency perspective in SMEs. Business Process Management Journal, 22(2), 368-382. doi: https://doi.org/10.1108/BPMJ-05-2015-0066

Pratono, A. H. (2018). Does firm performance increase with risk-taking behavior under information technological turbulence?: Empirical evidence from Indonesian SMEs. The Journal of Risk Finance, 19(4), 361-378. doi:https://doi.org/10.1108/JRF-10-2017-0170

Pratono, A. H. (2018). From social network to firm performance The mediating effect of trust selling capability and pricing capability. Management Research Review, 41, 680-700. doi:http://dx.doi.org/10.1108/MRR-03-2017-0080

Pratono, A. H., Darmasetiawan, N. K., Yudiarso, A., \& Jeong, B. G. (2019). Achieving sustainable competitive advantage through green entrepreneurial orientation and market orientation The role of inter-organizational learning. The Bottom Line, 32(1), 2-15. doi:https://doi.org/10.1108/BL-10-2018-0045

Pratono, A. H., Ratih, R. V., \& Arshad, D. (2018). Does Entrepreneurial Autonomy Foster SME Growth Under Technological Turbulence? The Empirical Evidence from Indonesia. Journal of Technology in Behavioral Science, 170-178. doi:https://doi.org/10.1007/s41347-018-0051-9

Rahab. (2012). Innovativeness Model Of Small And Medium Enterprises Based On Market Orientation and Learning Orientation: Testing Moderating Effect Of Business Operation Mode. Procedia Economics and Finance, 4, 97-109. doi:https://doi.org/10.1016/S22125671(12)00325-5

Wang, L., Wang, Y., Chen, Y., Pan, X., \& Zhang, W. (2020). Performance shaping factors dependence assessment through moderating and mediating effect analysis. Reliability Engineering and System Safety, 202, 1-10. doi:https://doi.org/10.1016/j.ress.2020.107034 
